\title{
Epileptic Encephalopathies in Childhood: The Role of Genetic Testing
}

\author{
Johannes R. Lemke, MD ${ }^{1}$ Steffen Syrbe, $\mathrm{MD}^{2}$ \\ 1 Institute of Human Genetics, University of Leipzig, Leipzig, Germany \\ 2 Department of Women and Child Health, Hospital for Children and \\ Adolescents, University of Leipzig, Leipzig, Germany
}

\begin{abstract}
Address for correspondence Johannes R. Lemke, MD, Institute of Human Genetics, University Hospital Leipzig, Philipp-Rosenthal-Str. 55, D04103 Leipzig, Germany (e-mail: johannes.lemke@medizin.uni-leipzig.de).
\end{abstract}

Semin Neurol 2015;35:310-322.

\begin{abstract}
Keywords

- epileptic encephalopathy

- infantile epilepsy

- molecular genetic testing

The epileptic encephalopathies comprise a heterogeneous group of neurodevelopmental disorders characterized by marked epileptic activity associated with developmental regression. The genetic confirmation and classification of a clinical diagnosis in an individual may provide certainty in treatment decisions, prognosis, and evaluation of seizure recurrence risks and may also prevent unnecessary diagnostic investigations. Furthermore, without genetic testing it is challenging to classify the epileptic encephalopathies based on clinical and electroencephalogram features alone.

The significant gain of knowledge of the past few years associated with improvement in genetic analyses allows for precise diagnoses in an increasing number of patients. As a consequence, known encephalopathies have been associated with even broader phenotypic ranges and novel entities constantly expand the spectrum of these disorders. Accordingly, many entities of this heterogeneous spectrum escape a precise classification using current nomenclatures.
\end{abstract}

Epileptic encephalopathies comprise a spectrum of disorders manifesting epilepsy and consequent psychomotor delay. According to the International League Against Epilepsy (ILAE), the epileptic activity itself most likely contributes to the severe cognitive and behavioral impairments, above and beyond that expected from the underlying pathology alone. ${ }^{1}$ Many forms of epileptic encephalopathy worsen over time and are refractory to pharmacotherapy.

Here we provide an overview of the growing field of epileptic encephalopathies that have no detectable structural brain lesions or metabolic abnormalities during the neonatal period, infancy, and childhood. Furthermore, we discuss a classification based on the clinical phenotype and onset versus a classification based on the genetic background of this group of disorders.

The ILAE classification is based primarily on the age of seizure onset, and it differentiates epileptic encephalopathy entities that have a specific clinical appearance or a particular pattern on electroencephalogram (EEG) ${ }^{1}$ :
- Neonatal period

- Early myoclonic encephalopathy

- Ohtahara syndrome

- Infancy

- Epilepsy of infancy with migrating focal seizures

- West syndrome

- Dravet syndrome

- Myoclonic encephalopathy in nonprogressive disorders

- Childhood

- Epilepsy with myoclonic atonic seizures

- Lennox-Gastaut syndrome

- Epileptic encephalopathy with continuous spike-andwave during sleep

- Landau-Kleffner syndrome

Epileptic encephalopathies that have no recognizable EEG pattern, particular seizure semiology, or additional specific features are not covered by the current ILAE classification.
Issue Theme Etiology of Epilepsy; Guest Editors: Philip Smith, MD, FRCP,

FAcadMEd, and Rhys Thomas, BSc, MRCP, MSc, PhD
Copyright @ 2015 by Thieme Medical Publishers, Inc., 333 Seventh Avenue, New York, NY 10001, USA. Tel: +1(212) 584-4662. 
Table 1 List of the known early infantile epileptic encephalopathy (EIEE) phenotypes according to Online Mendelian Inheritance in Man (OMIM), their respective causative genes, and the number of mutations listed in the Human Gene Mutation Database (HGMD)

\begin{tabular}{|c|c|c|c|}
\hline OMIM entity & Gene & $\begin{array}{l}\text { No. of published } \\
\text { mutations in } \\
\text { HGMD (as of May 6, } \\
\text { 2015) }\end{array}$ & Allelic phenotypes (in addition to EIEE) \\
\hline EIEE1 & $A R X$ & 69 & $\begin{array}{l}\text { Hydranencephaly with abnormal genitalia, } \\
\text { X-linked lissencephaly } 2 \text {, } \\
\text { X-linked mental retardation } 29, \\
\text { Partington syndrome, } \\
\text { Proud syndrome }\end{array}$ \\
\hline EIEE2 & CDKL5 & 216 & Angelman syndrome-like \\
\hline EIEE3 & SLC25A22 & 3 & \\
\hline EIEE4 & STXBP1 & 79 & \\
\hline EIEE5 & SPTAN1 & 10 & \\
\hline EIEE6 & SCN1A & 1098 & $\begin{array}{l}\text { Dravet syndrome, } \\
\text { Generalized epilepsy with febrile seizures plus type } 2 \text {, } \\
\text { Familial febrile seizures } 3 \mathrm{~A} \text {, } \\
\text { Familial hemiplegic migraine } 3\end{array}$ \\
\hline EIEE7 & KCNQ2 & 148 & $\begin{array}{l}\text { Benign neonatal seizures } 1 \text { (BFNS), } \\
\text { Myokymia }\end{array}$ \\
\hline EIEE8 & ARHGEF9 & 8 & \\
\hline EIEE9 & PCDH19 & 121 & \\
\hline EIEE10 & $P N K P$ & 8 & \\
\hline EIEE11 & SCN2A & 77 & Benign familial infantile seizures 3 \\
\hline EIEE12 & PLCB1 & 7 & \\
\hline EIEE13 & SCN8A & 27 & Cognitive impairment with or without cerebellar ataxia \\
\hline EIEE14 & KCNT1 & 15 & Nocturnal frontal lobe epilepsy 3 \\
\hline EIEE15 & ST3GAL3 & 3 & Autosomal recessive mental retardation 12 \\
\hline EIEE16 & TBC1D24 & 21 & $\begin{array}{l}\text { DOOR syndrome } \\
\text { Autosomal recessive deafness } 86 \\
\text { Familial infantile myoclonic epilepsy }\end{array}$ \\
\hline EIEE17 & GNAO1 & 6 & \\
\hline EIEE18 & $S Z T 2$ & 4 & \\
\hline EIEE19 & GABRA1 & 12 & $\begin{array}{l}\text { Childhood absence epilepsy, } \\
\text { Juvenile myoclonic epilepsy, Dravet syndrome }\end{array}$ \\
\hline EIEE20 & PIGA & 8 & \\
\hline EIEE21 & NECAP1 & 1 & \\
\hline EIEE22 & SLC35A2 & 8 & \\
\hline EIEE23 & DOCK7 & 4 & \\
\hline EIEE24 & HCN1 & 7 & Idiopathic generalized epilepsy \\
\hline EIEE25 & SLC13A5 & 4 & \\
\hline EIEE26 & KCNB1 & 4 & \\
\hline EIEE27 & GRIN2B & 26 & Autism spectrum disorders \\
\hline EIEE28 & WWOX & 18 & \\
\hline EIEE29 & AARS & 6 & \\
\hline EIEE30 & SIK1 & & \\
\hline
\end{tabular}

In contrast to the ILAE, Online Mendelian Inheritance in Man (OMIM; www.ncbi.nlm.nih.gov/omim) does not discriminate between clinical phenotypes, but classifies early- infantile epileptic encephalopathies exclusively according to the causative gene. This rapidly growing catalogue lists 30 such phenotypes (by May 2015). Some have so far only been 
reported as very rare and isolated cases, whereas others significantly overlap or form part of a continuum with different epileptic encephalopathies.

The allelic phenotypes include both incontrovertible monogenetic associations such as SCN1A and Dravet syndrome and as yet unproven risk alleles for complex phenotypes such as GABRA1 and juvenile myoclonic epilepsy.

The number of HGMD-listed mutations shows how often the disorder is diagnosed in the scientific literature. Due to allelic phenotypes, not all these mutations are associated with early infantile epileptic encephalopathy; for example, a minority of SCN1A mutations is associated with GEFS+ or hemiplegic migraine, and on the contrary, most KCNQ2 and SCN2A mutations cause benign familial epilepsy disordersnot early infantile epileptic encephalopathy ( - Table $\mathbf{1}$ ).

\section{Neonatal Period}

\section{Early Myoclonic Encephalopathy}

\section{Clinical Description}

Early (or neonatal) myoclonic encephalopathy, together with Ohtahara syndrome, shows a characteristic burst-suppression pattern on EEG. Phenotypic similarities can make it difficult to distinguish these disorders, and some authors consider them as a fluid continuum. ${ }^{2}$ Aicardi and Goutières first described early myoclonic encephalopathy in $1978 .{ }^{3}$ It usually starts in the first days of life with predominantly myoclonic seizures. Recurrent familial cases have been attributed mainly to inherited disorders of metabolism, especially nonketotic hyperglycinemia, pyridoxine, and pyridoxalphosphate-dependent epilepsy, sulfite-oxidase deficiency, and Menkes disease, as well as brain malformations. ${ }^{4-6}$ The seizures are usually described as myoclonic or erratic myoc- lonus. Although shifting focal myoclonias that affect different parts of the body, including the face and eyelids, are regarded as nonepileptic, focal motor seizures occur in more than $80 \%$ of patients and can include autonomic ictal manifestations and apnea (-Figs. 1 and 2) ${ }^{7,8}$ A neonatal burst-suppression pattern may evolve into hypsarrhythmia within the first months of life. The prognosis is very poor, with severe global developmental delay and a mortality rate of up to $50 \%$ during the first 2 years of life. ${ }^{2,6,7}$ Functional cortico-subcortical deafferentation from diffuse brain damage involving the brainstem and the white matter is regarded as the common underlying pathology, causing cortical hyperexcitability in early myoclonic encephalopathy. ${ }^{6,9,10}$

\section{Genetics}

The genetic background of early myoclonic encephalopathy is unclear. There is a single report of a patient carrying a de novo reciprocal chromosomal translocation with consecutive disruption of the ERBB4 gene, being putatively involved in neuromigration. ${ }^{11}$ Another report associated mutations in PIGA with early myoclonic encephalopathy and other forms of epileptic encephalopathy. ${ }^{12}$

\section{Ohtahara Syndrome or Early Infantile Epileptic Encephalopathy}

\section{Clinical Description}

Ohtahara and colleagues first described early infantile epileptic encephalopathy in 1976 as a disorder starting during the first 3 months of infancy. ${ }^{13}$ It primarily differs from epileptic encephalopathy of infantile onset (e.g., West syndrome) because of dominating tonic spasms, the variable seizure types including focal motor seizures, and its specific EEG pattern ( - Fig. 3) ${ }^{14}$ The cardinal EEG feature of Ohtahara

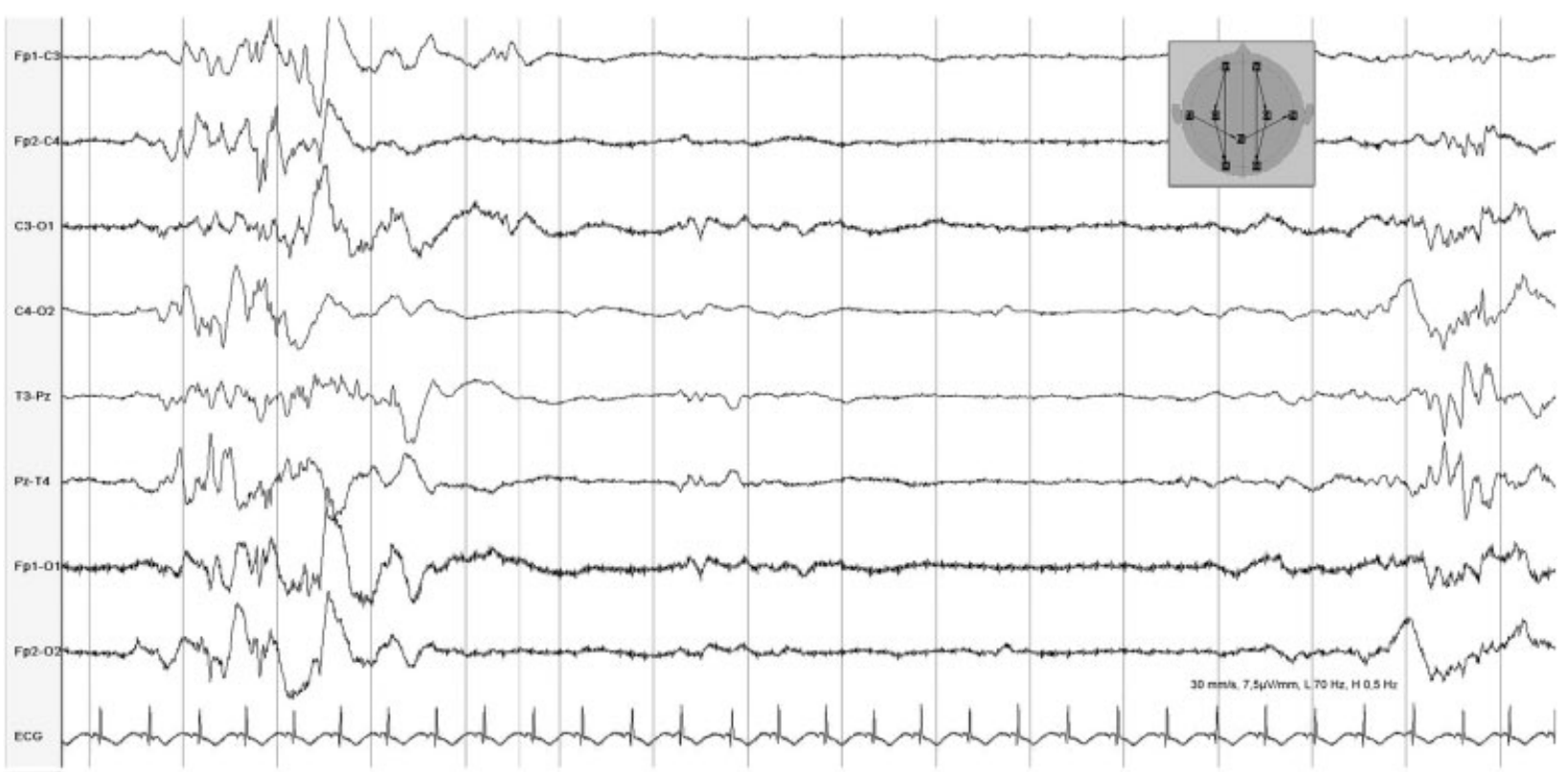

Fig. 1 Burst-suppression pattern in a patient with early myoclonic encephalopathy due to nonketotic hyperglycinemia. The patient showed shifting myoclonia, subtle seizures, and myoclonia including repetitive singultus. The burst-suppression pattern is more prominent during sleep. 


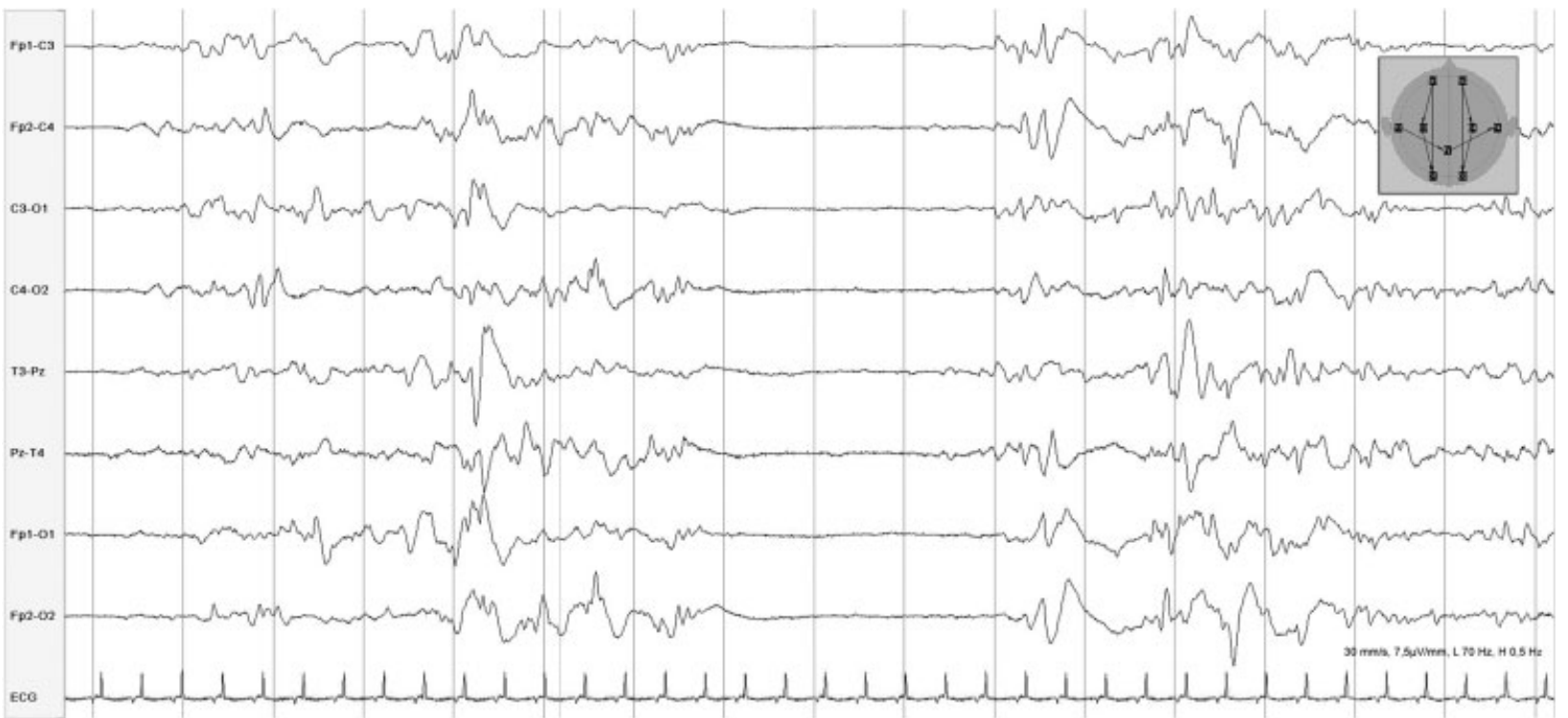

Fig. 2 Burst-suppression pattern in a girl with early myoclonic encephalopathy of unclear etiology. She presented with near-constant myoclonus and increased muscle tone associated with multifocal myoclonia as well as frequent seizure-related apnea. Brain magnetic resonance imaging showed cerebellar hypoplasia and progressive global atrophy.

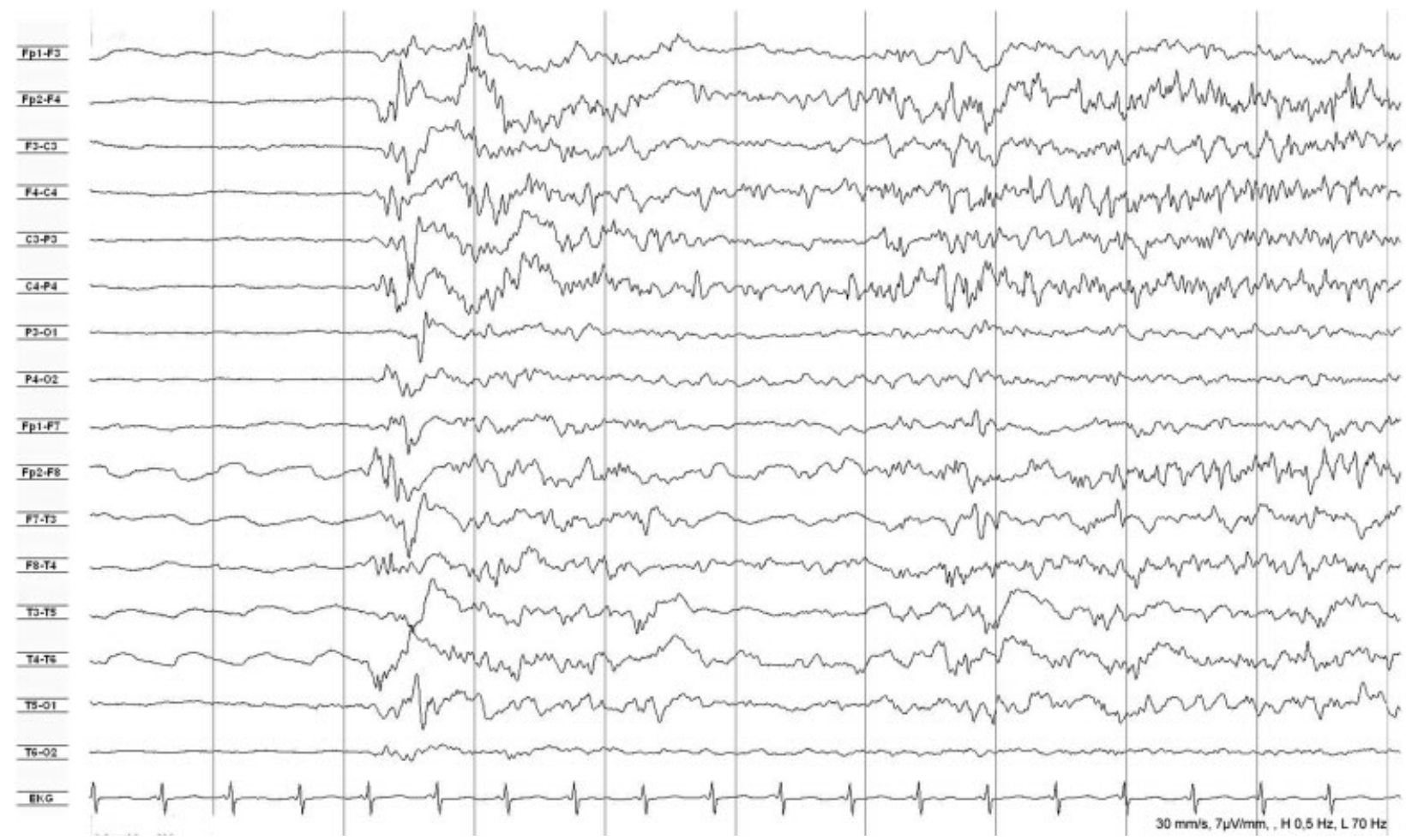

Fig. 3 Suppression period, followed by a burst of epileptic discharges that mark the onset of an ictal pattern in a 4-month-old girl with Ohtahara syndrome. Tonic seizures occurred at age 2 months, followed by multiple, predominantly focal seizure types. Brain magnetic resonance imaging showed severe brain atrophy during the first year of life. At 7 years old, she is severely impaired and has occasional seizures. 
Table 2 Ohtahara syndrome

\begin{tabular}{|l|l|}
\hline Mutation & Phenotype \\
\hline ARX & $\begin{array}{l}\text { Male patients with additional malformations, such as hypospadias, agenesis of corpus callosum, } \\
\text { lissencephaly, }{ }^{17} \text { progressive microcephaly, }{ }^{16} \text { or choreatic dystonia }{ }^{18}\end{array}$ \\
\hline STXBP1 & $\begin{array}{l}\text { Patients without significant malformations or dysmorphy, but frequently with early-onset movement } \\
\text { disorders. Seizure frequency may sometimes decrease during infancy. Patients with focal cortical } \\
\text { dysplasia may benefit from epilepsy surgery. } \\
\text { There were mutations in } 2 \text { out of } 6 \text { (33\%) Ohtahara patients and } 12 \text { out of 266 (4.5\%) of early infantile } \\
\text { epileptic encephalopathy patients. }\end{array}$ \\
\hline KCNQ2 & $\begin{array}{l}\text { No significant malformations or dysmorphy. Seizure frequency may sometimes decrease during } \\
\text { infancy. There were mutations in 19 out of } 164 \text { (11,6\%) of ElEE patients. }{ }^{21,22} \\
\text { Majority of KCNQ2 mutation carriers do not develop early infantile epileptic encephalopathy, but } \\
\text { develop benign neonatal seizures. }\end{array}$ \\
\hline CASK & Male patients with microcephaly and pontocerebellar hypoplasia. ${ }^{23}$ \\
\hline GNAO1 & Patients may present with movement disorders including dystonia, chorea, and athetosis. ${ }^{24}$ \\
\hline Copy number variations & Variable phenotypes; usually individual microdeletions \\
\hline
\end{tabular}

syndrome is a constant burst-suppression pattern during wakefulness and sleep. ${ }^{10}$ Trials with pyridoxine and pyridoxalphosphate are recommended, and phenobarbital, vigabatrin, or adrenocorticotropic hormone are used among others, but the seizures are usually refractory to pharmacotherapy and most patients have severely impaired development. Many patients die within the first months of life; others may evolve into West and Lennox-Gastaut syndrome during the course. ${ }^{6,8,14,15}$ Metabolic causes appear to be rare. Some patients demonstrate structural brain anomalies on magnetic resonance imaging (MRI), such as lissencephaly, hemimegalencephaly, or agenesis of the corpus callosum. ${ }^{16}$

\section{Genetics}

There are no published large-scale studies on the mutational spectrum of Ohtahara syndrome. Thus, our current knowledge is based upon small cohorts or isolated single case reports (-Table $\mathbf{2}$ ).

\section{Epilepsy of Infancy with Migrating Focal Seizures}

\section{Clinical Description}

Coppola and colleagues first described the rare syndrome of malignant migrating partial seizures or epilepsy in infancy (MMPSI) in $1995 .^{25}$ There are three well-characterized distinct stages of the disease:

1. Sporadic seizures usually occur within the first 6 months of life: These are mainly focal with rapid secondary generalization, often with autonomic features. The EEG at this early stage shows nonspecific diffuse slowing of background activity.

2. After a few weeks to months, the second "stormy" phase follows, with clusters of up to 30 focal polymorphic seizures per day that are often lateralized with deviation of the head and eyes as well as tonic and clonic jerks of extremities. During this phase, the EEG typically shows focal discharges that are "migrating" between cortical areas or develop independently in different areas of the same or opposite hemisphere. In general, seizures are resistant to therapy. Seizure phenotypes usually correlate with localization of ictal activity on EEG, thus producing clinical and electroencephalographic complex multifocal status epilepticus.

3. In the third period, at ages 2 to 5 years, seizures remit or occur only occasionally (sometimes triggered by illnesses), whereas severe developmental impairment becomes more prominent. ${ }^{25-27}$

\section{Genetics}

Epilepsy of infancy with migrating focal seizures has recently been associated with heterozygous mutations in KCNT1 (in up to $40 \%$ of cases) as well as compound heterozygous mutations in TBC1D24. Thus, MMPSI is heterogeneous and comprises both autosomal dominant and recessive entities. ${ }^{27-29}$ Single cases have shown mutations in PLCB1, SCN8A, SLC25A22, $S C N 2 A$, and $S C N 1 A$, whereas other studies could not confirm mutations in SCN1A, SCN2A, KCNQ2, and KCNQ3, as well as CLCN2 as major causes of epilepsy of infancy with migrating focal seizures. ${ }^{30-33}$

\section{Infancy}

\section{Infantile Spasms and West Syndrome}

\section{Clinical Description}

Infantile (or epileptic) spasms (ISs) are flexor spasms with bilateral tonic contractions. They are classified as a distinct seizure type, defined as unknown if generalized or focal according to the 2010 classification of the ILAE. ${ }^{1}$ The term West syndrome describes the triad of ISs together with a hypsarrhythmia pattern on EEG and behavioral or mental regression (-Fig. 4). ${ }^{1,34}$ In West syndrome, ISs appear in clusters (with up to 150 spasms) up to 30 times per day, starting between 3 and 9 months of age, with an incidence of 3 to 5 per 10,000 live births. ${ }^{8,34}$ Hypsarrhythmia is the typical 


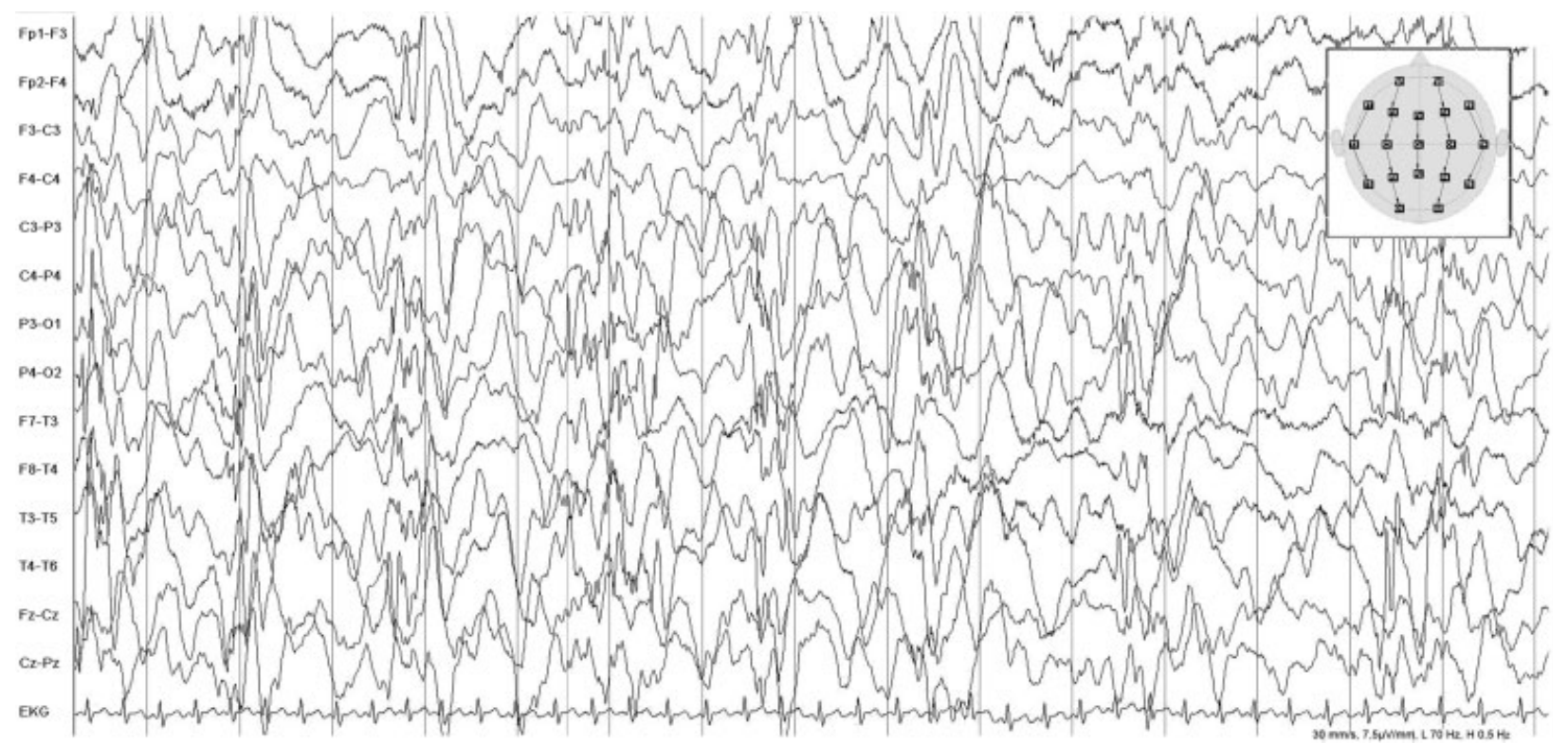

Fig. 4 Interictal electroencephalogram (EEG) in a 5-month-old girl with infantile spasms in the context of Aicardi syndrome. The EEG shows hypsarrhythmia (high-amplitude slow waves with irregular interspersed spikes and polyspikes) with right hemispheric dominance.

interictal EEG pattern consisting of chaotic generalized asynchronous high-amplitude slow and sharp waves with interspersed multifocal irregular spikes and polyspikes. Given the co-occurrence of developmental regression, West syndrome is the prototypical epileptic encephalopathy, arguing for a causal relationship between epileptic activity and progressive psychomotor deterioration. Recent studies in tuberous sclerosis complex-related West syndrome provided evidence that prophylactic treatment of epileptic discharges in EEG before the onset of epilepsy can help both mental development and epilepsy outcome. ${ }^{35}$ Adrenocorticotropic hormone or vigabatrin are the drugs of choice in West syndrome, controlling seizures in about two-thirds of patients. ${ }^{8}$

\section{Genetics}

The etiology of West syndrome and IS relate mainly to structural (e.g., due to tuberous sclerosis complex [TSC], hypoxic/ischemic encephalopathy, cortical dysgenesis) or metabolic abnormalities. Only $25 \%$ of cases are of unknown origin. ${ }^{36}$ In tuberous sclerosis complex-a multi-system or- gan disease often involving brain anomalies-West syndrome develops in $30 \%$ to $40 \%$ of patients; therefore, it is the single most prevalent genetic cause of West syndrome, accounting for around $7 \%$ of cases. 37,38

In the remainder of idiopathic cases, only a minority of genes have been repeatedly associated with West syndrome (-Table 3). Additionally, several isolated cases have been associated with mutations in a plethora of genes: CDKL5, SLC25A22, SPTAN1, PLCB1, ST3GAL3, HDAC4, and others. ${ }^{39-42}$ By only regarding clinical aspects (IS) or EEG features (hypsarrhythmia), this spectrum of genes is even wider and will most likely increase in the near future.

\section{Dravet Syndrome and Severe Myoclonic Epilepsy of Infancy}

\section{Clinical Description}

Charlotte Dravet initially described Dravet syndrome (DS) as severe myoclonic epilepsy of infancy in $1978 .{ }^{45}$ Dravet syndrome manifests in otherwise normal infants aged 3 to

Table 3 West syndrome

\begin{tabular}{|c|c|}
\hline Mutation & Phenotype \\
\hline$A R X$ & Often associated with brain malformations; see also Ohtahara syndrome \\
\hline STXBP1 & $\begin{array}{l}\text { Patients without significant malformations or dysmorphic features. } \\
\text { Mutations were found in } 1 \text { out of } 65 \text { ( } 2 \% \text { ) of patients with West syndrome. }{ }^{19} \text { Four out of } 6(67 \%) \text { STXBP1 } \\
\text { mutation carriers developed West syndrome. }{ }^{20}\end{array}$ \\
\hline DNM1 & $\begin{array}{l}\text { Severe psychomotor delay, no speech, muscular hypotonia. } \\
\text { Mutations were found in } 5 \text { out of } 356 \text { epileptic encephalopathy patients (1.4\%). All } 5 \text { patients had } \\
\text { infantile spasms, } 3 \text { had hypsarrhythmia. } 42,43\end{array}$ \\
\hline GRIN2B & Severe psychomotor delay, no speech, muscular hypotonia ${ }^{44}$ \\
\hline Copy number variations & Variable phenotypes; usually individual microdeletions \\
\hline
\end{tabular}


12 months, usually with febrile unilateral clonic or tonicclonic seizures and sometimes hemiclonic status epilepticus. Focal dyscognitive seizures and atypical absences also occur until 4 years of age. Most children show myoclonic seizures as originally described, differentiating between the classic severe myoclonic epilepsy of infancy phenotype and the borderline forms of Dravet syndrome. ${ }^{46,47}$

Seizures are commonly triggered by fever, infections, vaccination, hyperthermia, or photic stimulation. Interictal EEG is usually normal at onset. About 20\% to 25\% show generalized spike waves after photic stimulation. ${ }^{48,49}$ After 3 years of age, most affected children show EEG abnormalities; however, the interictal EEG can retain a normal background activity and many cases show no epileptiform activity. $8,46,47$

In general the brain MRI is normal, though occasionally there is hippocampal sclerosis or brain atrophy. ${ }^{46,47}$ Patients seem to benefit from early antiepileptic treatment, most often a combination of antiepileptic drugs, including valproic acid, benzodiazepines, bromide, topiramate, and stiripentol. However, it is essential to avoid sodium channel blockers, such as carbamazepine or lamotrigine, as these can worsen epilepsy and nonepileptic movement disorders. ${ }^{46,47}$

Vagus nerve stimulation and the ketogenic diet have recently been shown to be an alternative treatment option in epileptic encephalopathy including Dravet syndrome with minimal side effects and increasing quality of life. ${ }^{50}$ Children with Dravet syndrome typically show a slight delay in walking and clumsiness; the gait often becomes ataxic and some develop a spastic-like crouch pattern later in life. ${ }^{51}$ The seizures typically persist and intellectual outcome is unfavorable. $^{47}$

\section{Genetics}

Dravet syndrome is caused by mutations in SCN1A in at least $75 \%$ of cases. ${ }^{52}$ Several other genes have been associated with Dravet or Dravet-like phenotypes, such as PCDH19 (females only) $)^{53}$ or less frequent in $S C N 1 B, S C N 2 A$, and GABRG2. More recently, mutations in GABRA1 and STXBP1 have been associated with classic Dravet syndrome, ${ }^{54}$ whereas mutations in CHD2 have been detected in late-onset cases. ${ }^{55}$ Mutations in HCN1 have been found in patients diagnosed with Dravet syndrome, but presenting with a different progression and a more severe degree of intellectual deficit. ${ }^{56}$

Thus, SCN1A-negative Dravet (-like) patients show a high genetic heterogeneity; it is proposed that the term Dravet syndrome be reserved for SCN1A mutation carriers only.

Variants in SCN9A have been described as putatively disease-modifying factors in addition to mutations in SCN1A. ${ }^{57}$ However, this and other putative modifiers remain to be replicated in large cohorts. Because the quality and sensitivity of molecular genetic diagnostics have significantly improved in the last decade, it may be reasonable to question "old" negative SCN1A results in patients with classic Dravet syndrome. Several false-negative findings have been reported recently due to improvement of sequencing techniques. $^{58}$

\section{Childhood and School Age}

\section{Lennox-Gastaut Syndrome}

\section{Clinical Description}

The description of a severe childhood epilepsy and its electroencephalographic features described by Lennox and Davis in 1950 and by Gastaut et al in 1966 led to the definition of Lennox-Gastaut syndrome as part of the epileptic encephalopathies in childhood. ${ }^{59,60}$ The diagnostic criteria of typical Lennox-Gastaut syndrome consist of

1. Multiple epileptic seizures including axial tonic, atonic, and atypical absence seizures

2. Electroencephalogram abnormalities with frontally accentuated bursts of slow spike-waves during wakefulness and bursts of fast rhythmic activity during sleep

3. A slowness in intellectual growth and associated personality disorders 8,61

The age at onset is 3 to 6 years. Lennox-Gastaut syndrome may be preceded by nonepileptic and/or epileptic encephalopathy, such as Ohtahara or West syndrome. Drop attacks from axial tonic or (myoclonic-) atonic seizures are among the predominating seizure types together with atypical absence seizures and nonconvulsive status epilepticus. ${ }^{8,61}$ Nearly all patients have severe intellectual disability and refractory epilepsy. In addition, there may be significant overlap with other epileptic encephalopathies, such as Dravet syndrome, epilepsy with myoclonic-atonic seizures, Angelman syndrome, and others.

As pharmacoresistance is a predominant feature of Lennox-Gastaut syndrome, a combination of several antiepileptic drugs is usually inevitable with valproic acid, lamotrigine, topiramate, and benzodiazepines being of value, as well as rufinamide (and the cautiously used felbamate) are frequently prescribed drugs. ${ }^{61}$ The literature about pharmacotherapy in Lennox-Gastaut syndrome seems to reflect more the innovations of the antiepileptics than a formal therapeutic approach, and it is still debatable whether to reduce or increase the antiepileptic medications in affected individuals with refractory seizures. ${ }^{8}$

\section{Genetics}

The etiology of Lennox-Gastaut syndrome comprises a broad range of structural, metabolic, and primarily monogenetic pathologies, as well as tumor, infection, trauma, and intoxication. However, both structural malformations (e.g., cortical dysgenesis, neuronal migration disorders) and metabolic disorders (including mitochondriopathies) may similarly have been caused by monogenetic defects.

Genes that have been repeatedly associated with LennoxGastaut syndrome comprise SCN1A, GABRB3, CHD2, and DNM1. ${ }^{42,43,62}$ Single Lennox-Gastaut syndrome cases have also been reported to show mutations in MAPK10, ALG13, SCN2A, SCN8A, RYR3, and ST3GAL3. Some of those genes have been associated with West syndrome too, reflecting its transition into Lennox-Gastaut syndrome. 


\section{Epilepsy with Myoclonic-Atonic Seizures (Doose Syndrome, MAE)}

\section{Clinical Description}

Epilepsy with myoclonic-atonic seizures is a generalized epilepsy and belongs to the myoclonic epilepsies of childhood. ${ }^{1}$ It was first described by Kruse (1968) and Doose (1970) and occurs with an explosive onset in otherwise healthy children with a male predominance. ${ }^{63,64}$ Myoclonic seizures that can be subtle and difficult to recognize followed by an atonic, postmyoclonic phase are the hallmark of the syndrome, leading to typical drop attacks or head-nodding attacks. Patients also display generalized tonic-clonic, tonic, and atypical absence seizures (-Fig. 5). The onset is usually around age 1 to 5 years. ${ }^{65}$ The seizures are often difficult to treat, and besides valproic acid and ethosuximide, ketogenic diet has shown to help in epilepsy with myoclonic-atonic seizures. The seizure outcome is very good, with $90 \%$ of patients becoming seizure free within 3 years. The cognitive outcome is highly variable, with up to $40 \%$ developing mild to severe intellectual disability. ${ }^{65}$

\section{Genetics}

Little is known on the etiology of epilepsy with myoclonicatonic seizures. Fourteen to $32 \%$ of affected children have a family history of idiopathic epilepsy. ${ }^{66} \mathrm{~A}$ few children resembling epilepsy with myoclonic-atonic seizures belong to large
GEFS + families carrying SCN1B missense mutations. ${ }^{67}$ Other cases may carry mutations in SLC2A1. ${ }^{68}$ A recent study identified six individuals carrying de novo mutations in SLC6A1 among 160 MAE patients (4\%). ${ }^{69}$ Additionally, one out of 39 MAE patients (2.5\%) was found to carry a de novo mutation in $K C N A 2 .^{70}$

\section{Epileptic Encephalopathy with Continuous Spike-and- Wave during Sleep and Landau-Kleffner Syndrome}

\section{Clinical Description}

This is a disorder with intellectual disability and language deficits associated with a subclinical EEG pattern during sleep, first described by Patry et al in 1971, and referred to "epileptic encephalopathy with continuous spike-and-wave during sleep" by Tassinari et al in 1977. ${ }^{71-73}$ Together with the acquired epileptic aphasia / Landau-Kleffner syndrome, continuous spike-and-wave during sleep is recognized as an electroclinical syndrome by the ILAE. ${ }^{1}$ Both syndromes share the main features of marked sleep activation of mainly focal epileptic discharges into a continuous or near-continuous spike-and-wave pattern together with a regression in different aspects of development. ${ }^{8}$ The degree of bioelectrical status during sleep remains a controversial topic. The diagnosis is considered in patients with (1) spike-and-wave pattern occupying more than $85 \%$ of nonrapid eye-movement sleep for more than a month, or (2) a significant increase of

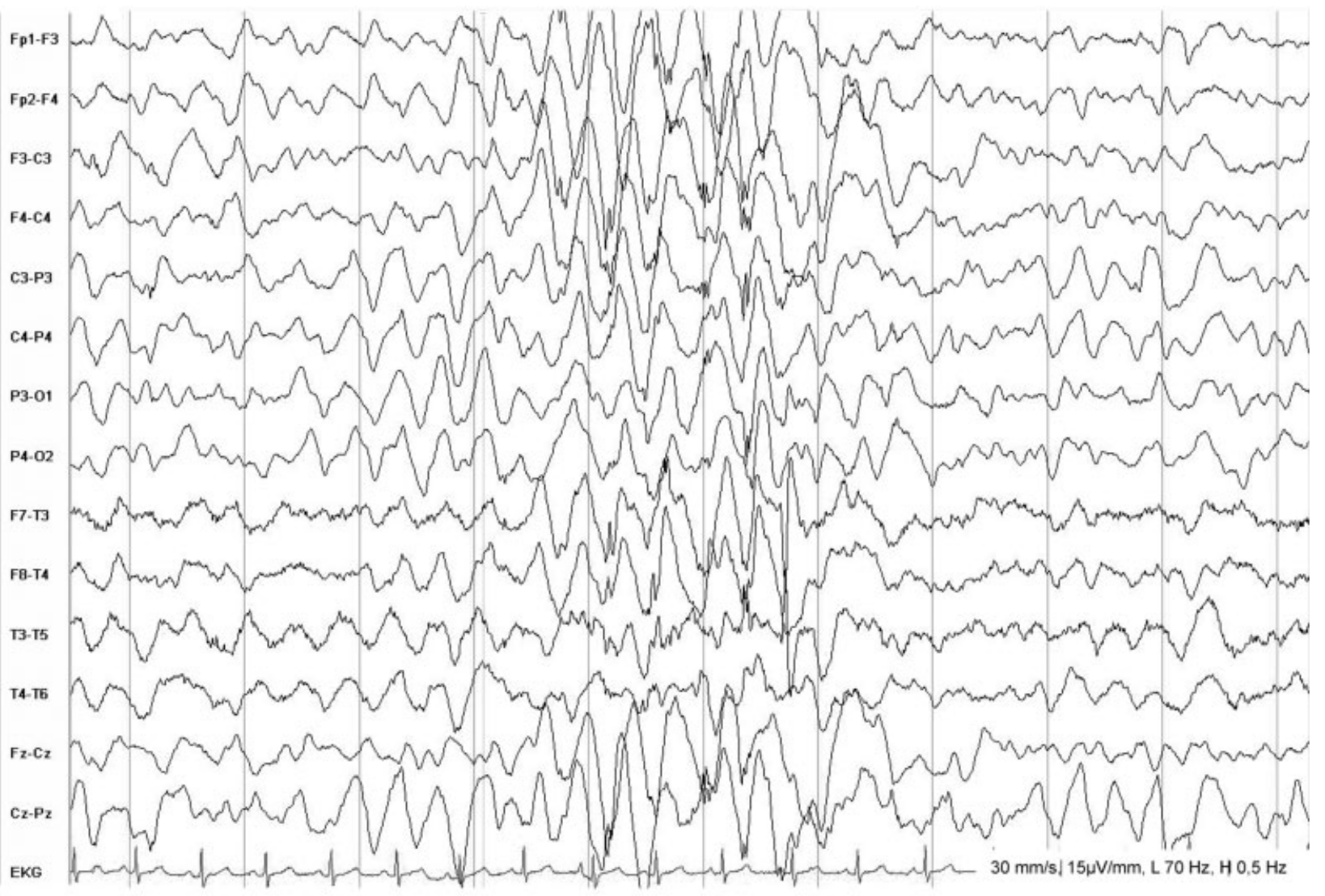

Fig. 5 Electroencephalogram (EEG) of a 4-year-old girl with idiopathic epilepsy with myoclonic-atonic seizures displaying slowing of background activity and typical generalized spikes and polyspikes. Polyspikes are the EEG correlate of myoclonic seizures while the following slow wave correlates with the atonic component. 


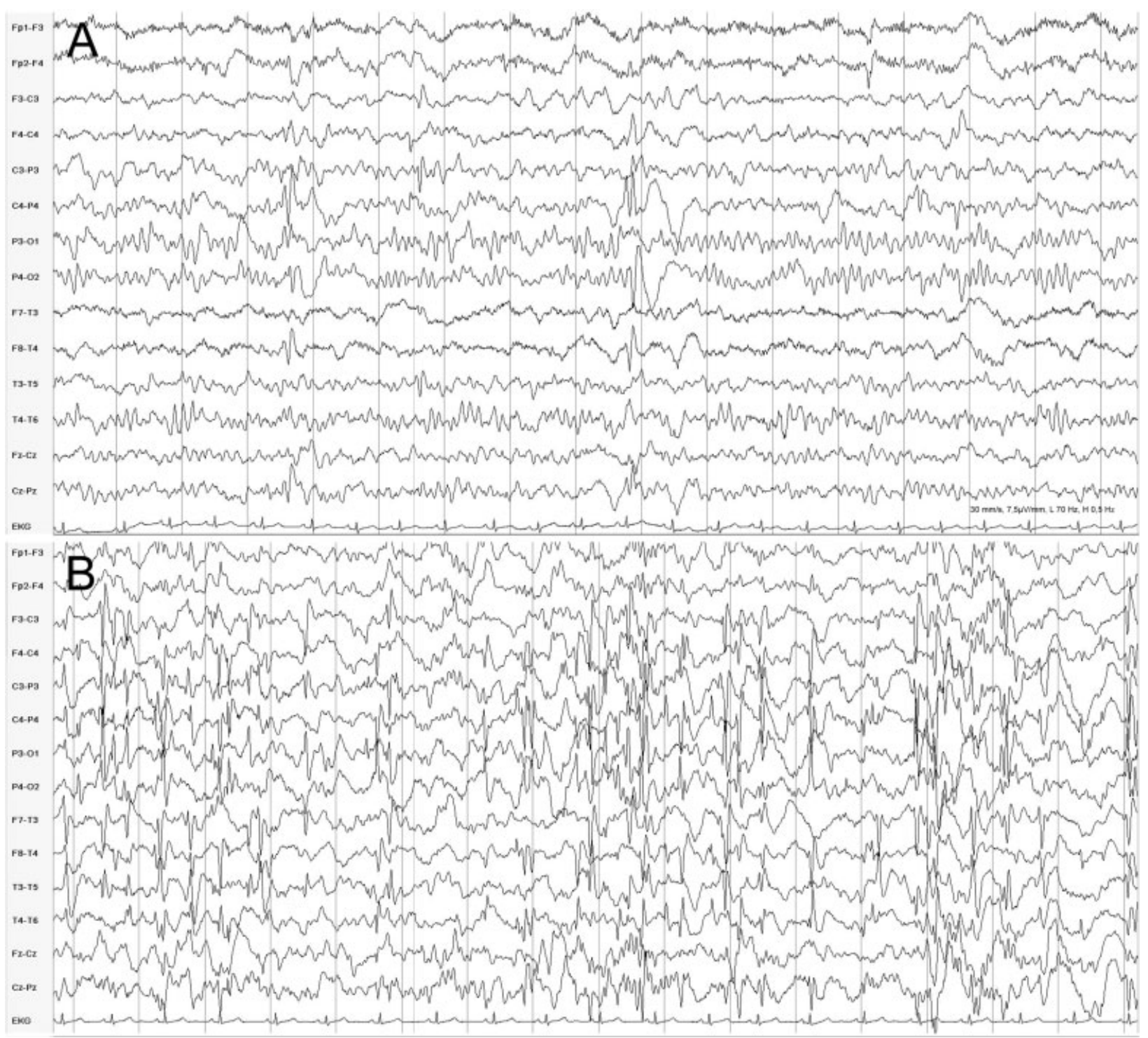

Fig. 6 Electroencephalogram during wakefulness (A) and sleep in a 7-year-old boy, initially referred for attention-deficit-hyperactivity disorder. Multifocal singular sharp waves (A) are markedly activated during sleep into a pattern of near-continuous spike-and-wave activity (B). Despite several treatment trials including sulthiame, levetiracetam, oxcarbazepine, and methylprednisolone, the continuous spike-and-wave during sleep pattern remained. His learning disabilities became apparent and school performance declined significantly. The genetic diagnosis remains unclear.

EEG abnormalities during sleep associated with intellectual and behavioral impairment, as well as language deficits and transient motor impairment (-Fig. 6). ${ }^{8,72,73}$

Continuous spike-and-wave during sleep and LandauKleffner syndrome belong to the spectrum of genetic focal epilepsies of childhood with overlap to benign epilepsy with centrotemporal (rolandic) spikes. ${ }^{74}$ One-third to onehalf of children with continuous spike-and-wave during sleep have neurologic abnormalities before disease onset, with mainly pre- or perinatally acquired brain lesions. ${ }^{8,72,73}$ In the other half, genetic factors most likely contribute to the phenotype. Landau-Kleffner syndrome occurs in previously healthy children aged 2 to 8 years. Half of affected children develop seizures as the first symptom of disease; the other half show exclusively progressive linguistic disturbances that commonly start with an inabil- ity to understand spoken words that evolves into sensory and expressive aphasia (-Fig. 7).

Seizures are infrequent in continuous spike-and-wave during sleep and Landau-Kleffner syndrome. This is particularly so in continuous spike-and-wave during sleep, where they can occur before and after diagnosis with mainly nocturnal focal seizures but also generalized tonic-clonic and absence seizures. Treatment options include all classical antiepileptic medications; however, most authors suggest trying sulthiame, benzodiazepines alone, or combined with valproic acid and corticosteroids. ${ }^{73}$ The continuous spikeand-wave during sleep pattern and seizures usually remit in puberty. Simultaneously, neuropsychological function may improve; residual impairment correlates with the length of continuous spike-and-wave during sleep and early age at diagnosis. $^{8,72}$ 


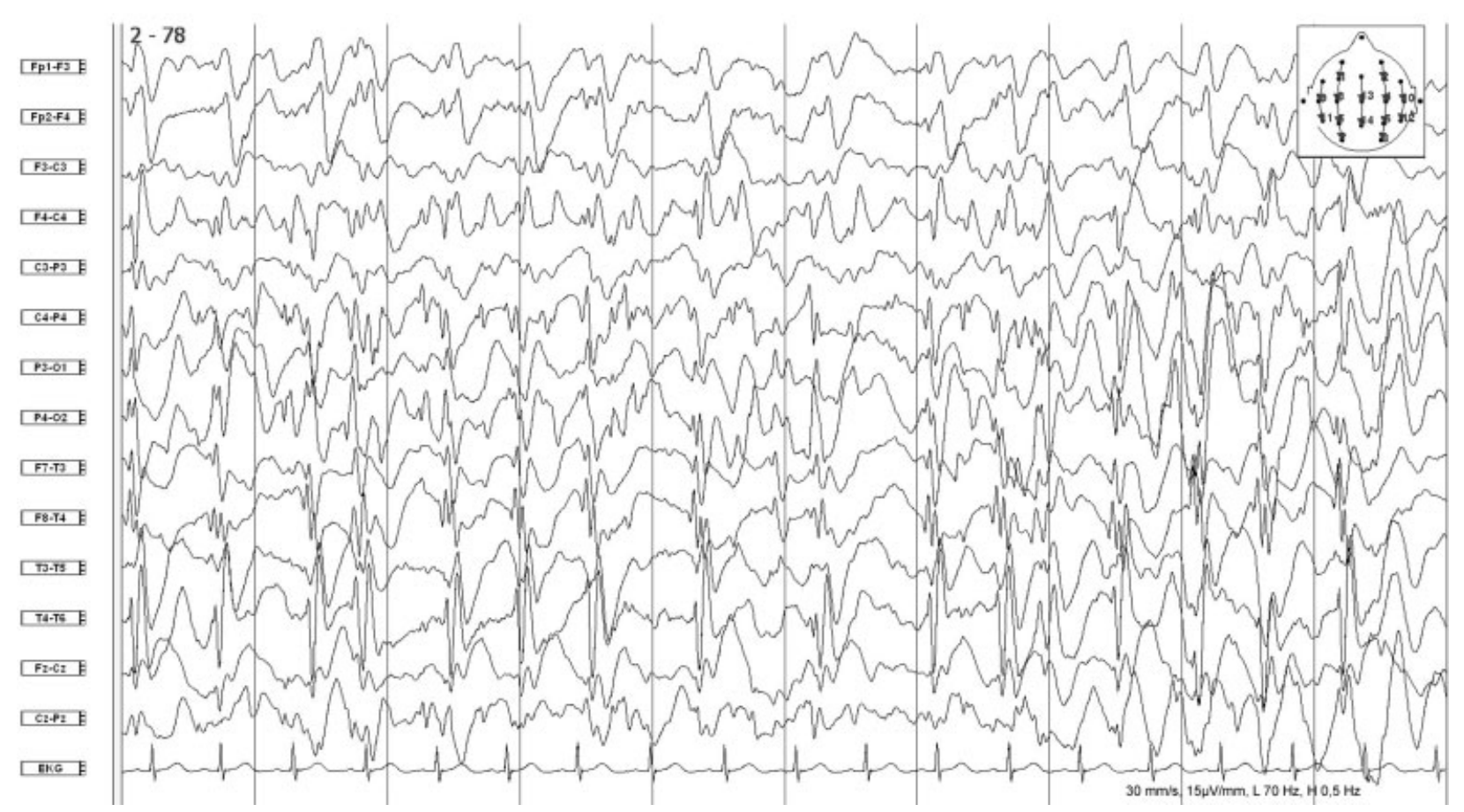

Fig. 7 Continuous spike-and-wave pattern during sleep-onset nonrapid eye-movement sleep in a boy with Landau-Kleffner syndrome. At the age of 4 years the caregivers observed progressive limitation of speech recognition followed by deterioration of expressive speech. Communication was finally restricted to manual gestures. After use of sulthiame, levetiracetam, and dexamethasone over 2 years, the continuous spike-and-wave during sleep pattern resolved and verbal communication resumed. At the age of 14 , although his electroencephalogram is normal, he has mild speech and mental impairment.

\section{Genetics}

Individuals with idiopathic focal epilepsy may also have relatives with epilepsy. However, the severity and clinical presentation may vary considerably between affected individuals, even within the same family. Mutations in GRIN2A, a gene encoding the NMDA receptor subunit GluN2A has recently been identified to account for up to $20 \%$ of cases with continuous spike-and-wave during sleep and LandauKleffner syndrome. ${ }^{75-77}$ Mutation detection rates were higher in familial compared with isolated cases. In 5 to $10 \%$ of cases with milder epilepsies of the same spectrum, such as atypical partial epilepsy and benign epilepsy with centrotemporal spikes, the individual disorder has similarly been assigned to mutations in GRIN2A. ${ }^{75}$

\section{Discussion}

The ILAE classification is a pragmatic grouping of the heterogeneous spectrum of epileptic encephalopathies defined by clinical and electroclinical characteristics that are "reliably identified," but do not reflect the specific etiology. ${ }^{1}$ There is no differentiation of channelopathies, synaptopathies, or epileptic encephalopathies due to structural anomalies, though this could have significant implications for prognosis and therapeutic decisions. As an example, seizures in Ohtahara syndrome due to STXBP1 or KCNQ2 mutations may reduce in frequency during infancy, and they may require other therapeutic strategies when compared with $A R X$-related burst-suppression epilepsy associated with abnormal gyration. Likewise, the transition from Ohtahara into West syndrome and from West into Lennox-Gastaut syndrome has been well described in numerous cases. Thus, a patient with Lennox-Gastaut syndrome may previously have had Ohtahara and West syndrome, and may therefore be etiologically very different from other Lennox-Gastaut syndrome patients without such history. Hence, without genetic classification of an epileptic encephalopathy, the prognosis on the individual course and treatment outcome of the disorder remains empirical. Furthermore, physicians are often confronted with patients suffering from less distinct epileptic encephalopathy phenotypes that can barely be assimilated into the current ILAE schemes.

The phenotypic series of early infantile epileptic encephalopathy according to OMIM represents a quite different way to group epileptic encephalopathies. In contrast to Ohtahara et al, OMIM uses the term early infantile epileptic encephalopathy not only for neonatal epilepsy with a specific EEG pattern and marked developmental delay, ${ }^{13}$ but for a far broader spectrum of disorders with onset within the first year of life ( - Table 1). Within this phenotypic series, epilepsy aspects are barely considered, allowing for a more comprehensive delineation of the phenotype (beyond epilepsy) attributed to a specific gene. As an example, early infantile epileptic encephalopathy-4 (EIEE4) is caused by mutations in STXBP1 and may result in (1) Ohtahara syndrome, (2) West syndrome, (3) Dravet syndrome, (4) severe epilepsy without distinct EEG features, (5) nonsyndromal intellectual disability without seizures, and (6) autism spectrum disorders and others. $^{20,54,78}$ The OMIM phenotypic series does not include epileptic encephalopathy phenotypes with onset beyond the 
first year of life. Therefore, both the ILAE and the OMIM classification only depict a narrow spectrum out of the broad group of epileptic encephalopathies.

An alternative to established classifications might be a system primarily focusing on genetic aspects and only secondarily, on phenotypic features. Onset, phenotypic appearance, and severity would have less importance compared with pathophysiology and its implications on possible therapeutic aspects as well as prognostic assertions. Overlap and transition of different phenotypes within one genetic entity would also be better acknowledged by a classification primarily considering genetic etiology. Moreover, emphasis on pathophysiology reflects the increasing importance of personalized therapy in patients with epileptic encephalopathy. Several therapies can help by specifically targeting individual genetic defects, such as quinidine in KCNT1 encephalopathy, ${ }^{79,80}$ retigabine in KCNQ2 encephalopathy, ${ }^{81}$ memantine in GRIN2A encephalopathy, ${ }^{82}$ and the ketogenic diet in SLC2A1-related epilepsy. Thus, genetic testing can significantly influence clinics and therapy of epileptic encephalopathy; it can be expected that this development will increasingly gain importance in the years to come.

\section{References}

1 Berg AT, Berkovic SF, Brodie MJ, et al. Revised terminology and concepts for organization of seizures and epilepsies: report of the ILAE Commission on Classification and Terminology, 2005-2009. Epilepsia 2010;51(4):676-685

2 Mizrahi EMM. Early severe neonatal and infantile epilepsies. In: Bureau M, Genton P, Dravet CH, Delgado-Escueta AV, Tassinari CA, Thomas P, Wolf P, eds. Epileptic Syndromes in Infancy, Childhood and Adolescence. 5th ed. London: John Libbey Eurotext Ltd; 2012

3 Aicardi J, Goutieres F. [Neonatal myoclonic encephalopathy (author's transl)]. Rev Electroencephalogr Neurophysiol Clin 1978; 8(1):99-101

4 Aicardi J. Epilepsy in brain-injured children. Dev Med Child Neurol 1990;32(3):191-202

5 Plecko B. Pyridoxine and pyridoxalphosphate-dependent epilepsies. Handb Clin Neurol 2013;113:1811-1817

6 Ohtahara S, Yamatogi Y. Epileptic encephalopathies in early infancy with suppression-burst. J Clin Neurophysiol 2003;20(6): 398-407

7 Murakami N, Ohtsuka Y, Ohtahara S. Early infantile epileptic syndromes with suppression-bursts: early myoclonic encephalopathy vs. Ohtahara syndrome. Jpn J Psychiatry Neurol 1993; 47(2):197-200

8 Panayiotopoulos CP. The epilepsies: seizures, syndromes and management. Oxfordshire, UK: Bladon Medical Publishing; 2005

9 Hirose M, Haginoya K, Yokoyama H, et al. Functional cortical deafferentation from the subcortical structures in a patient with early myoclonic encephalopathy: a functional neuroimaging study. Epilepsia 2010;51(4):699-702

10 Ohtahara S, Yamatogi Y. Ohtahara syndrome: with special reference to its developmental aspects for differentiating from early myoclonic encephalopathy. Epilepsy Res 2006;70(Suppl 1): S58-S67

11 Backx L, Ceulemans B, Vermeesch JR, Devriendt K, Van Esch H. Early myoclonic encephalopathy caused by a disruption of the neuregulin-1 receptor ErbB4. Eur J Hum Genet 2009;17(3): $378-382$
12 Kato M, Saitsu H, Murakami Y, et al. PIGA mutations cause earlyonset epileptic encephalopathies and distinctive features. Neurology 2014;82(18):1587-1596

13 Ohtahara S, Ishida T, Oka E, Yamatogy Y, Inoue H. On the specific age dependent epileptic syndrome: the early-infantile epileptic encephalopathy with suppression-burst. No To Hattatsu 1976; 8:270-279

14 Yamatogi Y, Ohtahara S. Early-infantile epileptic encephalopathy with suppression-bursts, Ohtahara syndrome; its overview referring to our 16 cases. Brain Dev 2002;24(1):13-23

15 Kato M, Saitoh S, Kamei A, et al. A longer polyalanine expansion mutation in the ARX gene causes early infantile epileptic encephalopathy with suppression-burst pattern (Ohtahara syndrome). Am J Hum Genet 2007;81(2):361-366

16 Giordano L, Sartori S, Russo S, et al. Familial Ohtahara syndrome due to a novel ARX gene mutation. Am J Med Genet A 2010; 152A(12):3133-3137

17 Uyanik G, Aigner L, Martin P, et al. ARX mutations in X-linked lissencephaly with abnormal genitalia. Neurology 2003;61(2): 232-235

18 Guerrini R, Moro F, Kato M, et al. Expansion of the first PolyA tract of ARX causes infantile spasms and status dystonicus. Neurology 2007;69(5):427-433

19 Weckhuysen S, Holmgren P, Hendrickx R, et al. Reduction of seizure frequency after epilepsy surgery in a patient with STXBP1 encephalopathy and clinical description of six novel mutation carriers. Epilepsia 2013;54(5):e74-e80

20 Deprez L, Weckhuysen S, Holmgren P, et al. Clinical spectrum of early-onset epileptic encephalopathies associated with STXBP1 mutations. Neurology 2010;75(13):1159-1165

21 Weckhuysen S, Mandelstam S, Suls A, et al. KCNQ2 encephalopathy: emerging phenotype of a neonatal epileptic encephalopathy. Ann Neurol 2012;71(1):15-25

22 Weckhuysen S, Ivanovic V, Hendrickx R, et al; KCNQ2 Study Group. Extending the KCNQ2 encephalopathy spectrum: clinical and neuroimaging findings in 17 patients. Neurology 2013;81(19): 1697-1703

23 Saitsu H, Kato M, Osaka H, et al. CASK aberrations in male patients with Ohtahara syndrome and cerebellar hypoplasia. Epilepsia 2012;53(8):1441-1449

24 Nakamura K, Kodera H, Akita T, et al. De Novo mutations in GNAO1, encoding a Goo subunit of heterotrimeric $G$ proteins, cause epileptic encephalopathy. Am J Hum Genet 2013;93(3):496-505

25 Coppola G, Plouin P, Chiron C, Robain O, Dulac O. Migrating partial seizures in infancy: a malignant disorder with developmental arrest. Epilepsia 1995;36(10):1017-1024

26 Coppola G. Malignant migrating partial seizures in infancy: an epilepsy syndrome of unknown etiology. Epilepsia 2009;50 (Suppl 5):49-51

27 McTague A, Appleton R, Avula S, et al. Migrating partial seizures of infancy: expansion of the electroclinical, radiological and pathological disease spectrum. Brain 2013;136(Pt 5):1578-1591

28 Barcia G, Fleming MR, Deligniere A, et al. De novo gain-of-function KCNT1 channel mutations cause malignant migrating partial seizures of infancy. Nat Genet 2012;44(11):1255-1259

29 Ishii A, Shioda M, Okumura A, et al. A recurrent KCNT1 mutation in two sporadic cases with malignant migrating partial seizures in infancy. Gene 2013;531(2):467-471

30 Ohba C, Kato M, Takahashi S, et al. Early onset epileptic encephalopathy caused by de novo SCN8A mutations. Epilepsia 2014; 55(7):994-1000

31 Poduri A, Heinzen EL, Chitsazzadeh V, et al. SLC25A22 is a novel gene for migrating partial seizures in infancy. Ann Neurol 2013; 74(6):873-882

32 Dhamija R, Wirrell E, Falcao G, Kirmani S, Wong-Kisiel LC. Novel de novo SCN2A mutation in a child with migrating focal seizures of infancy. Pediatr Neurol 2013;49(6):486-488 
33 Coppola G, Veggiotti P, Del Giudice EM, et al. Mutational scanning of potassium, sodium and chloride ion channels in malignant migrating partial seizures in infancy. Brain Dev 2006;28(2):76-79

34 Lux AL, Osborne JP. A proposal for case definitions and outcome measures in studies of infantile spasms and West syndrome: consensus statement of the West Delphi group. Epilepsia 2004; 45(11):1416-1428

35 Jóźwiak S, Kotulska K, Domańska-Pakieła D, et al. Antiepileptic treatment before the onset of seizures reduces epilepsy severity and risk of mental retardation in infants with tuberous sclerosis complex. Eur J Paediatr Neurol 2011;15(5):424-431

36 Nabbout R, Dulac O. Epileptic encephalopathies: a brief overview. J Clin Neurophysiol 2003;20(6):393-397

37 Mettin RR, Merkenschlager A, Bernhard MK, et al. Wide spectrum of clinical manifestations in children with tuberous sclerosis complex-follow-up of 20 children. Brain Dev 2014;36(4): 306-314

38 Osborne JP, Lux AL, Edwards SW, et al. The underlying etiology of infantile spasms (West syndrome): information from the United Kingdom Infantile Spasms Study (UKISS) on contemporary causes and their classification. Epilepsia 2010;51(10):2168-2174

39 Paciorkowski AR, Thio LL, Dobyns WB. Genetic and biologic classification of infantile spasms. Pediatr Neurol 2011;45(6): 355-367

40 Kurian MA, Meyer E, Vassallo G, et al. Phospholipase C beta 1 deficiency is associated with early-onset epileptic encephalopathy. Brain 2010;133(10):2964-2970

41 Edvardson S, Baumann AM, Mühlenhoff M, et al. West syndrome caused by ST3Gal-III deficiency. Epilepsia 2013;54(2):e24-e27

42 Allen AS, Berkovic SF, Cossette P, et al; Epi4K Consortium; Epilepsy Phenome/Genome Project. De novo mutations in epileptic encephalopathies. Nature 2013;501(7466):217-221

43 Euro E-RESC; EuroEPINOMICS-RES Consortium; Epilepsy Phenome/Genome Project; Epi4K Consortium. De novo mutations in synaptic transmission genes including DNM1 cause epileptic encephalopathies. Am J Hum Genet 2014;95(4):360-370

44 Lemke JR, Hendrickx R, Geider K, et al. GRIN2B mutations in West syndrome and intellectual disability with focal epilepsy. Ann Neurol 2014;75(1):147-154

45 Dravet C. Les epilepsies graves de l'enfant. Vie Med 1978; 8:543-548

46 Brunklaus A, Ellis R, Reavey E, Forbes GH, Zuberi SM. Prognostic, clinical and demographic features in SCN1A mutation-positive Dravet syndrome. Brain 2012;135(Pt 8):2329-2336

47 Dravet C, Bureau M, Oguni H, Cokar O, Guerrini R. Dravet syndrome. (Severe myoclonic epilepsy in infancy). In: Bureau $M$, Genton P, Dravet CH, Delgado-Escueta AV, Tassinari CA, Thomas P, Wolf P, eds. Epileptic Syndromes in Infancy, Childhood and Adolescence. 5th ed. London: John Libbey Eurotext Ltd; 2012

48 Dalla Bernardina B, Capovilla G, Gattoni MB, Colamaria V, Bondavalli S, Bureau M. [Severe infant myoclonic epilepsy (author's transl)]. Rev Electroencephalogr Neurophysiol Clin 1982;12(1): 21-25

49 Bureau M, Dalla Bernardina B. Electroencephalographic characteristics of Dravet syndrome. Epilepsia 2011;52(Suppl 2):13-23

50 Orosz I, McCormick D, Zamponi N, et al. Vagus nerve stimulation for drug-resistant epilepsy: a European long-term study up to 24 months in 347 children. Epilepsia 2014;55(10):1576-1584

51 Rodda JM, Scheffer IE, McMahon JM, Berkovic SF, Graham HK. Progressive gait deterioration in adolescents with Dravet syndrome. Arch Neurol 2012;69(7):873-878

52 Claes L, Del-Favero J, Ceulemans B, Lagae L, Van Broeckhoven C, De Jonghe P. De novo mutations in the sodium-channel gene SCN1A cause severe myoclonic epilepsy of infancy. Am J Hum Genet 2001; 68(6):1327-1332

53 Depienne C, Bouteiller D, Keren B, et al. Sporadic infantile epileptic encephalopathy caused by mutations in PCDH19 resembles Dravet syndrome but mainly affects females. PLoS Genet 2009;5(2): e1000381

54 Carvill GL, Weckhuysen S, McMahon JM, et al. GABRA1 and STXBP1: novel genetic causes of Dravet syndrome. Neurology 2014;82(14):1245-1253

55 Suls A, Jaehn JA, Kecskés A, et al; EuroEPINOMICS RES Consortium. De novo loss-of-function mutations in CHD2 cause a fever-sensitive myoclonic epileptic encephalopathy sharing features with Dravet syndrome. Am J Hum Genet 2013;93(5):967-975

56 Nava C, Dalle C, Rastetter A, et al; EuroEPINOMICS RES Consortium. De novo mutations in HCN1 cause early infantile epileptic encephalopathy. Nat Genet 2014;46(6):640-645

57 Singh NA, Pappas C, Dahle EJ, et al. A role of SCN9A in human epilepsies, as a cause of febrile seizures and as a potential modifier of Dravet syndrome. PLoS Genet 2009;5(9):e1000649

58 Lemke JR, Riesch E, Scheurenbrand T, et al. Targeted next generation sequencing as a diagnostic tool in epileptic disorders. Epilepsia 2012;53(8):1387-1398

59 Lennox WG, Davis JP. Clinical correlates of the fast and the slow spike-wave electroencephalogram. Pediatrics 1950;5(4):626-644

60 Gastaut H, Roger J, Soulayrol R, et al. [Epileptic encephalopathy of children with diffuse slow spikes and waves (alias "petit mal variant") or Lennox syndrome]. Ann Pediatr (Paris) 1966;13(8): 489-499

61 Crespel A, Gelisse P, Nikanorova M, Ferlazzo E, Genton P. LennoxGastaut syndrome. In: Bureau M, Genton P, Dravet CH, DelgadoEscueta AV, Tassinari CA, Thomas P, Wolf P, eds. Epileptic Syndromes in Infancy, Childhood and Adolescence. 5th ed. London: John Libbey Eurotext Ltd; 2012

62 Lund C, Brodtkorb E, Øye AM, Røsby O, Selmer KK. CHD2 mutations in Lennox-Gastaut syndrome. Epilepsy Behav 2014;33:18-21

63 Kruse R. [The myoclonic astatic petit mal. Clinical course of small epileptic seizures in childhood. With an introduction by Prof. Dr. Dietrich Janz]. Monogr Gesamtgeb Neurol Psychiatr 1968; 124:1-126

64 Doose H, Gerken H, Leonhardt R, Völzke E, Völz C. Centrencephalic myoclonic-astatic petit mal. Clinical and genetic investigation. Neuropadiatrie 1970;2(1):59-78

65 Oguni H, Tanaka T, Hayashi K, et al. Treatment and long-term prognosis of myoclonic-astatic epilepsy of early childhood. Neuropediatrics 2002;33(3):122-132

66 Kaminska A, Ickowicz A, Plouin P, Bru MF, Dellatolas G, Dulac O. Delineation of cryptogenic Lennox-Gastaut syndrome and myoclonic astatic epilepsy using multiple correspondence analysis. Epilepsy Res 1999;36(1):15-29

67 Wallace RH, Wang DW, Singh R, et al. Febrile seizures and generalized epilepsy associated with a mutation in the $\mathrm{Na}+-$ channel beta1 subunit gene SCN1B. Nat Genet 1998;19(4): 366-370

68 Mullen SA, Suls A, De Jonghe P, Berkovic SF, Scheffer IE. Absence epilepsies with widely variable onset are a key feature of familial GLUT1 deficiency. Neurology 2010;75(5):432-440

69 Carvill GL, McMahon JM, Schneider A, et al. Mutations in the GABA transporter SLC6A1 cause epilepsy with myoclonic-atonic seizures. Am J Hum Genet 2015;96(5):808-815

70 Syrbe S, Hedrich UB, Riesch E, et al. De novo loss- or gain-offunction mutations in KCNA2 cause epileptic encephalopathy. Nat Genet 2015;4(4):393-399

71 Patry G, Lyagoubi S, Tassinari CA. Subclinical "electrical status epilepticus" induced by sleep in children. A clinical and electroencephalographic study of six cases. Arch Neurol 1971;24(3): 242-252

72 Tassinari CA, Daniele O, Gambarelli F, Bureau-Paillas M, Robaglia L, Cicirata F. [Excessive 7-14-sec positive spikes during REM sleep in monozygotic non-epileptic twins with speech retardation (author's transl)]. Rev Electroencephalogr Neurophysiol Clin 1977; 7(2):192-193 
73 Tassinari CA. Encephalopathy related to status epilepticus during slow sleep (ESES) including Landau-Kleffner syndrome. In: Bureau $\mathrm{M}$, Genton P, Dravet $\mathrm{CH}$, Delgado-Escueta AV, Tassinari CA, Thomas P, Wolf P, eds. Epileptic Syndromes in Infancy, Childhood and Adolescence. 5th ed. London: John Libbey Eurotext Ltd; 2012

74 Tovia E, Goldberg-Stern H, Ben Zeev B, et al. The prevalence of atypical presentations and comorbidities of benign childhood epilepsy with centrotemporal spikes. Epilepsia 2011;52(8):1483-1488

75 Lemke JR, Lal D, Reinthaler EM, et al. Mutations in GRIN2A cause idiopathic focal epilepsy with rolandic spikes. Nat Genet 2013; 45(9):1067-1072

76 Lesca G, Rudolf G, Bruneau N, et al. GRIN2A mutations in acquired epileptic aphasia and related childhood focal epilepsies and encephalopathies with speech and language dysfunction. Nat Genet 2013;45(9):1061-1066

77 Carvill GL, Regan BM, Yendle SC, et al. GRIN2A mutations cause epilepsy-aphasia spectrum disorders. Nat Genet 2013;45(9): 1073-1076
78 Rauch A, Wieczorek D, Graf E, et al. Range of genetic mutations associated with severe non-syndromic sporadic intellectual disability: an exome sequencing study. Lancet 2012;380(9854): 1674-1682

79 Milligan CJ, Li M, Gazina EV, et al. KCNT1 gain of function in 2 epilepsy phenotypes is reversed by quinidine. Ann Neurol 2014; 75(4):581-590

80 Bearden D, Strong A, Ehnot J, DiGiovine M, Dlugos D, Goldberg EM. Targeted treatment of migrating partial seizures of infancy with quinidine. Ann Neurol 2014;76(3):457-461

81 Orhan G, Bock M, Schepers D, et al. Dominant-negative effects of KCNQ2 mutations are associated with epileptic encephalopathy. Ann Neurol 2014;75(3):382-394

82 Pierson TM, Yuan H, Marsh ED, et al; PhD for the NISC Comparative Sequencing Program. GRIN2A mutation and early-onset epileptic encephalopathy: personalized therapy with memantine. Ann Clin Transl Neurol 2014;1(3):190-198 